\title{
Making humans better and making better humans
}

\author{
MAIRI LEVITT AND FIONA K. O’NEILL ${ }^{1}$
}

\begin{abstract}
The last 10 years has seen the development and deployment of new biotechnologies not just as potential treatments but also as potential enhancements. The definition and differentiation of treatment (therapy) from enhancement is an ongoing clinical, ethical and social debate that ranges across a proliferating number of convergent technologies. Many of these innovations will 'come-on-line' as present generations of young people will be reaching adulthood and considering parenthood. This paper reports on a project that explored the possibilities for human enhancement with young people in order to gather their attitudes towards enhancement and the types of arguments/reasoning they employ when thinking about the possibilities and the techniques. The project focused on if/how distinctions are made between treatment and enhancement, between the different techniques that might be used for enhancement (genetic and non-genetic) and perceptions of risks and benefits. The young people's viewpoints, their methods of reasoning and underlying values are compared with those of bioethicists writing on the topic.
\end{abstract}

\section{Introduction}

The debate about whether a distinction can and should be drawn between the treatment and enhancement of human beings has become more pressing with the completion of the Human Genome Project and other convergent technologies, especially those within neuroscience. The distinction is, of course, relevant to debates about ethics and governance if it is assumed that treatment is unproblematic or less problematic, whereas anything defined as enhancement has to be carefully considered. However, gene therapy, stem cells therapy and neuroscientific technologies remain controversial, despite their potential to treat serious disease or disability, partly because they also have this potential to be used for enhancement.

Bioethicists divide into those who find the distinction between treatment and enhancement untenable and support the use of biotechnology for both, ${ }^{2}$ and, those who argue that, although enhancement and treatment are difficult to distinguish, a distinction should be sought and any use of biotechnology for enhancement should be very carefully considered and regulated. ${ }^{3}$ However, the boundaries of medicine change over time. ${ }^{4}$

Those who are pro-enhancement tend to argue first of all that there is no clear line to be drawn between treatment and enhancement, which makes efforts at regulation extremely difficult. All those who support enhancement have to deal with the 20th century Western history of previous attempts to improve the human race through eugenic programmes, most notoriously (but not, of course, confined to) in Nazi Germany. They argue that a clear separation can be made between old-style paternalistic state-enforced eugenics and eugenics based on individual parental 
choice. The debate then becomes one about the freedom of individuals and families to choose. Agar goes so far as to argue that enhancement should operate on market principles; those who have the money and want to pay for the product should be free to do so ${ }^{5}$. While concerns are raised about 'designer babies' the counter argument is that it is unethical not to seek to improve on nature and 'make the best babies you can. ${ }^{6}$ Savulescu coined the term 'procreative beneficence' to indicate the moral duty on parents to select the best baby they can by IVF and preimplantation genetic diagnosis and, with other bioethicists, argues that parents should be trusted to choose for their children. ${ }^{7}$ The whole idea of enhancement is hardly new; parents have always tried to enhance their (potential) children, whether through their choice of 'mate' or, postnatally, through their purchase of private schooling, music lessons or educational holidays. ${ }^{8}$ We might argue about the fairness of the 'freedom to choose' but we accept these inequalities as part of parental choice and the right to a private family life. Those who are pro-enhancement argue that in time new ways of enhancement will probably become more accessible, just as older types of enhancement, including education, have done. Furthermore new forms of enhancement may seem strange and even wrong now but will become accepted over time in the same way as other technologies.

On the other hand, those who are critical of the application of enhancement technologies argue that we can and should draw a clear line between enhancement and treatment and that harms can result for individuals and society even if treatments/enhancements are chosen by individuals rather than being forced upon them. They point to a prospect of genetic inequalities that may be harder to ameliorate than other inequalities. Measures can be taken to restrict educational advantage and tax those with high incomes, but enhancements could lead to an underclass, with the long-term prospect of two separate species of humans; the gene rich and the gene poor. Currently, 'designing' babies is in fact limited to choosing from potential babies using IVF and embryo selection or prenatal diagnosis and selective termination. There are groups opposed both to abortion and to IVF.

From a disability rights perspective the labelling of some conditions as disabilities that merit a termination of pregnancy is problematic, as are attempts to 'normalise' the disabled body. Children with acondroplasia may be subjected to operations to lengthen limbs or Down's children to facial surgery. Available technologies are being applied to conditions newly identified as 'medical'. Children who are below average in height have been treated with growth hormone, originally used for children with a medically recognised condition, and Ritalin is widely used beyond the identified client group. Parents and doctors have argued that short people are disadvantaged in life; as are those who find it difficult to concentrate. This illustrates the point that enhancements gain their own momentum; the promise of a better life makes it difficult to refuse enhancements, particularly when parents are choosing for their children. Fukuyama argues that there will be in effect a "genetic arms race" with parents forced to 'choose' to prevent their child being disadvantaged. As an enhancement becomes normal then it is no longer advantageous and so something further will be sought. As Hirsch wrote:"If everyone stands on tiptoe, no one sees better." Those who oppose genetic human enhancements therefore consider it 
essential to set limits to enhancement procedures to prevent increased social inequality and to protect children from enhancements chosen by their parents. Allowing individual choice can lead to societal changes, as seen in countries where couples using sex selection to choose boys has led to a skewed sex ratio.

Other possible risks are the removal of some genetic mutations that have another, unknown, potentially useful function and a reduction in genetic diversity. For those taking a precautionary line on enhancement the liberal market model is not one that should be applied in this area. If techniques are developed without regulation the agenda for medicine will be set by commercial interests looking for profit. Medical technology and skills will be diverted to unnecessary procedures when treatments that would cure disease or restore function are still not available to all. Finally, there is the argument that we need to decide on our basic human values and protect them. ${ }^{10}$ There is a danger that biotechnology will cause us to lose our humanity. ${ }^{11}$

There are others who advocate caution whilst not opposing enhancement in principle. They argue that we should consider what a good human life is and look at individual needs in relation to other people, since the good life is lived with others. ${ }^{12}$ Glover adopts a compromise position by which parents can make positive choices of characteristics but choices are limited by some regulation of options in the public interest, including the need to prevent social inequalities. ${ }^{13}$ The difficulty of drawing a line between treatment and enhancement, or ethical and non-ethical uses of technology, is acknowledged but that does not mean that dialogue should be abandoned.

Stock argues that 'the current discussion about human enhancement .....[is] at a fundamental level ... about philosophy and religion. It is about what it means to be human, about our vision of the human future'. ${ }^{14}$ The media and public debate on enhancement in the UK has mainly been in response to specific cases or to proposed changes in regulation. Recent topics have included the increase in requests for preimplantation diagnosis for cancers, for stem cell therapies and for licences to create hybrid embryos, while a flood of discussion was prompted by regulatory changes contained in the Human Fertilisation and Embryology Act, 2008. ${ }^{15}$ Coverage included criticism of proposals that could be seen as tampering with human life, stories of patients who might benefit and speculation about possible enhanced futures. Whilst there are specific interest groups, including those with a religious affiliation, which have strong views on the application of genetic technologies to enhance human life, they may not raise the questions of most interest to those who do not subscribe to these groups.

The purpose of this project was to encourage young people aged 10-18 to think about the issues involved in human enhancement using real life and science fiction examples. The issues raised moved from a general focus on the body and technology to the more specific issues of genomics and other convergent technologies. Through collecting their responses to imagined and actual scenarios the focus was on the forms of argumentation the young people use, the implicit or explicit values and assumptions they make and how their reasoning relates to that presented in the bioethical literature. For example, do they use standard ethical theories and arguments 
as found in the literature? Do they see a need to distinguish between treatment and enhancement? Do they believe in genetic exceptionalism? In terms of theories do they use consequentialist or deontological arguments or apply ethical principles to specific cases? Do they prioritise individual choice and/or bring in broader social and political factors in their answers?

It is now taken for granted within the UK that some form of public consultation is an essential part of developing policy within science and technology. Bodies like the HFEA and the Nuffield Council on Bioethics carry out regular public consultations, and funding bodies including the Wellcome Trust and the ESRC support diverse public engagement activities with specific funding streams. The motivations for public engagement are diverse; the hope that it will increase public confidence and trust in science, the view that engaging the public is as an essential part of democracy, and the contention that the public's own expertise is of value to scientists and policy makers. ${ }^{16}$ For the public to be involved in the development of research agendas it is essential that they are involved 'upstream', as the science and technology develops, rather than simply when it is ready to be applied, or already applied. There is also a need for the results of public engagement to be incorporated into decision-making processes. ${ }^{17}$ Most public engagement is undertaken with adults but there is an argument that being 'upstream' in the sense of engaging with younger people is particularly valuable since they will experience the consequences of decisions being made now about research and applications.

\section{The sample}

The data was collected from three comprehensive schools and one primary school in the North West of England. The original intention was to include the top year of primary school (age 10/11), first year secondary (age 11/12) and the final years of secondary school (age 16/18); however 30 students age 13/14 were also included at the request of one school. The schools chosen were non-selective (by academic or religious criteria) and included schools in different settings within the same county (rural, small town, suburban and urban). All the schools had children from different social class backgrounds and one secondary school had significant numbers from nonwhite minority ethnic groups. Although the sample was diverse there is no claim that the findings are generalisable. The school-based sessions were mainly conducted in religious studies classes or personal, social and health education (PSHE), with two sessions in 'A' level philosophy and one science class (the year 9 students). The year 9 group were therefore distinctive by subject and age, but for the others there were differences in responses by age and gender but not by subject. In all, 225 students completed questionnaires (103 male, 121 female, one unknown). Responses were analysed using SPSS including the coding of the open-ended questions by themes.

\section{Methodology}

The research in school was carried out during a normal lesson slot; taking 75 minutes in the primary school and 50 minutes in the secondary schools. 35 of the young people had the same session as part of an ESRC-funded outreach session at Lancaster University in a 75 minute slot. The session divided the stimulus material into sections, coherent with the questionnaire. PowerPoint was used to introduce examples for 
discussion and included film clips from Robots and Bicentennial Man (all groups); and The Island (16-18 year olds only). ${ }^{18}$ The film clips had to be age appropriate and accessible while introducing and conveying a clear point of moral decision making with regard to how we consider our bodies. Robots was used to stimulate thinking about the possibility of 'upgrades' for humans. Bicenntenial Man showed a robot gradually acquiring human characteristics and raised the question if or when a parttechnological being became human and whether people should be free to choose what enhancements they want. Older children were shown an additional clip from The Island to help them think about the use of technologies to solve problems, whether it matters what methods are used and to consider again whether treatment and enhancement can and/or should be distinguished. Students were given a questionnaire with summaries of the main points made in each section and questions to debate in groups. They were asked to record their personal responses through drawing and/or writing and were encouraged to give reasons for their answers.

The worksheet/questionnaires were the same for all ages except for the two additional questions for the 16-18 year old students based on the movie clip from The Island, which probed students' ideas about the issue of a treatment-enhancement distinction. The PowerPoint assisted in methodically introducing each group of questions, breaking the overall task down into manageable sections and allowing for changes in the pace and style of engagement. This approach supported student engagement, individually and in groups.

Section 1 asked for students' own ideas for 'upgrading' humans, starting with a clip from the film Robots in which robots are exhorted to 'upgrade'. Follow-up questions asked whether they thought other people would want 'upgrades' and whether people should be able to choose. By using cartoon about robots rather than human beings this clip did not suggest enhancements directly applicable to humans but left it open to the young people to come up with their own ideas. Section 2 considered the case of Paralympic gold medal winner Oscar Pistorius, who has Flex-Foot Cheetah ${ }^{\circledR}$ prosthetic legs and had hoped to compete in the Beijing Olympic Games. Although Pistorius's technology is biomechanical rather than genetic, it engenders the same type of basic moral questions and reasoning that would be encountered in decisions about genetic enhancements. Older students (16-18) were specifically asked whether a distinction can be made between treatment and enhancement. Section 3 looked at whether students distinguished between different methods of human enhancement, genetic and non-genetic.

The final section was about students' ideas on regulation in this field and whether any regulation is needed.

\section{Section 1: 'If we could 'upgrade' humans, what 'upgrades' would you want, if any?}

All sessions started with a clip from the film Robots, in which robots are exhorted to 'upgrade'. "Why be you, when you can be new!"19 The most popular enhancement among younger children was being able to fly and, among younger boys to have metal 
prostheses or to be invincible. Older students were more likely to choose enhancements of physical appearance and mental abilities. Overall, however, 18 per cent of all boys and a quarter of girls did not even want to imagine any enhancements because they saw them as unnatural, immoral or simply unnecessary. Typical responses from a younger and older boy respectively were;

I don't want any upgrades because it [is] imorle (immoral) to change who you are. You are born and your special, if you 'upgrade' humans everyone would want the same thing, it's stupid (boy, age 11/12)

In terms of upgrades that enhance beyond human capacities I would not require any upgrades. The search for perfection is created by a desire to be 'better'. This can never be fulfilled in a sense. What is important is to be content with ones current situation.

(boy, age 17/18)

Whether or not students wanted enhancements themselves, they expected other people to want them and thought they should be allowed to choose. A selection of the 11-12 year olds' responses show the priorities young people expect others to have, concerns about appearance linked to avoidance of bullying or lack of friends and the worries about getting old, perhaps expressed by their parents.

I think that most people would want an upgrade to help them lose weight or change the way they look

Don't get bags and wrinkles on your face

To be liked and involved, and also to be better looking, because people can feel left out and ugly compared to people around them.

Taller or smaller anything they're not happy with really

(Year 7 students)

\section{Section 2: Oscar Pistorius: the Paralympian}

Oscar Pistorius is an athlete born with no lower limbs who uses two Cheetah ${ }^{\circledR}$ FlexFeet ${ }^{\circledR} .{ }^{20}$ However, both disabled and able-bodied athletes have argued that the FlexFeet give Pistorius an advantage, as the blades he uses are longer than are necessary, allowing him to cover more ground in each stride and making him taller than he would have been if he had been born with legs. Having discussed whether Pistorius had been treated for a disability or enhanced beyond his abilities, the students were asked to consider the case of a single-limbed Paralympian who wished to have a healthy limb amputated and replaced with blades to gain a similar advantage and a short able-bodied athlete who wanted a double amputation to give an increased stride. Although Pistorius had a non-genetic treatment-enhancement, it was used as a real life example raising questions of risk, harm, fairness and choice.

Here a student articulates Hirsch's remark: 'if everyone stands on tiptoe, no one sees better' ${ }^{21}$ :

[Replacing 1 leg] I think it is acceptable for this to occur (his human foot being replaced with an artificial one). His decision is not affecting anybody else therefore why not? However, there are 
obvious problems. It is like a stack of dominoes. One person will follow another. Where will it stop? People may continuously start adopting the process for self-satisfaction. Thus, in the long term it is wrong. [Replacing 2 legs] No this shouldn't happen. Being perfectly normal is a blessing therefore why should people alter it? Also, again in the long run this could cause problems as an increasing number of people want to do the same. (Female, age 17/18)

As noted earlier, Frank talks of our right to reshape our bodies to improve our life chances and realise our ambitions. ${ }^{22}$ However, as the student above has written, the uncoerced choices of numerous individuals can in time constitute a socially accepted and expected trend. ${ }^{23}$

Several points were picked up by most students regardless of their age, gender or subject group. They acknowledged that a single-limbed disabled athlete might wish to amputate a leg, even if they saw such a choice as selfish, unnatural and unnecessary, but some felt this choice should not be allowed. In contrast most students saw the short athlete's choice to amputate both healthy legs as ridiculous, selfish, unnatural or unnecessary and something that should not be allowed. In a similar way the public have expressed disgust at self-demand amputation for those with body dysmorphic disorder. As Bayne and Levy have noted: "The desire for amputation of a healthy limb is at odds with current conceptions of the ideal body image. The preference for bodily integrity is deep-seated in normal human beings, and advertising does much to reinforce such norms. We therefore think it unlikely that the desire for amputation will proliferate". ${ }^{24}$

People will be afended [offended] by someone cutting off a healthy leg for an artificial one, and people with no legs will become afended (male, age 13/14)

[double amputation] I think its sick because his normal feet are fine. (male, age 11/12)

I think its bad because s/he is cutting both s/he's legs and your disabling yourself. (male, age 13/14)

Secondary issues included the consequences of making such choices and the harm or regret this might engender, as there would be no going back.

The short, able-bodied athlete should stick with what he has otherwise it would open the floodgates for everyone else to chop their legs off. I think it would also outrage people who have no legs as people are wasting their legs. What would he do when he is not in the Olympics any more? (Female, age 13/14)

In regard to Pistorius the general consensus was that he is disabled and having artificial legs is a treatment. But his ability to extend his prosthetics beyond the given parameters one would allometrically expect for his body was an enhancement. A common comment on the distinction, in this case from a girl aged 13 or 14, was between 'having a problem solved' and bring 'given something that is 'better than normal' echoing Carl Elliot's distinction in Better Than Well. ${ }^{25}$ 
If someone is being treated they are having things that they need to be [done]. Where as if you have an enhancement you are having things made 'better' than normal. (Year 12 female)

For Harris and others an enhancement is "good for you" and "by definition an improvement on what went before" ${ }^{26}$ However, some students employed this definition pejoratively arguing that:

An enhancement improves by adding something that's not needed. A treatment improves by treating a problem and replenishing it back to its natural state. No enhancement should be needed otherwise human rules aren't clear. (Male, age 17/18)

Others hinted at the reasons that make the treatment-enhancement distinction problematic including changes in perception and classification;

We need to distinguish between what is classed as a method for medical difficulty and methods of enhancement. However, it would prove very difficult to do. In a way we choose what treatment we want and not want. (Female, age 16/17)

Many of those who struck a note of caution when it comes to the slippery slope between treatment and enhancement suggested we should take a precautionary caseby-case approach, at least in the first instance.

It depends on the circumstances: In some cases there are elements of both e.g. if you had a brace it would not only make you look better (enhancement) but it would treat them in the process. However if someone had upgrades they may use them for the wrong reasons. It's up to the person who wants it done. If it's their individual decision then they should go by that. It's a need and want situation. However, the doctor will know your medical and physical state. They would need to advise you. (Female, age 13/14)

Yes we do need to make a distinction. To do this though we can't make absolute rules, each case would have to be analysed on its own individual merits. (Male, age 17/18)

\section{Section 3: Does it matter how human enhancement is achieved?}

The facilitator introduced the topic by saying to the group: "So does it matter how we enhance or treat people, what methods we use? Let's try what is called a hypothetical question here. I'm going to give you a situation that could happen but hasn't happened yet, and I want you to imagine your response to it." Students were asked to give their preferences between different imaginary ways of reducing human aggression using the following wording.

Imagine a world with a global govern ment. If we were all to ag ree that $\mathrm{m}$ aking the hum an race less aggressive was a 'good thing' would it matter how we did th is? Which m ethod would you choose and why? 
The alternatives offered were:

[To] genetically modify all humans (before birth) to be less aggressive.

[To] modify all humans, by putting a chemical into the world's water supply that would reduce aggressive tendencies by a fixed amount forever, as soon as that chemical reaches the brain.

or [to] provide drugs to the world's population (by post) that would reduce aggressive tendencies, but only if taken twice a day. ${ }^{27}$

The expectation we had, which was fulfilled, was that the genetic modification would be the least popular of the options and the non-genetic, non-permanent enhancement would be the most popular. However, the most popular choice of all was to reject all options. The question provoked discussions regarding free will and the freedom to act, drawing in concomitant political issues. The idea of a global consensus that would lead to a blanket policy regarding a bodily enhancement was seen as an infringement of freedom of choice and untenable in terms of implementation. Amongst the secondary students, this provoked discussion of the World Health Organisation's global vaccination programs, and the issue of parental choice.

I think in some cases people ought to be forced to comply e.g. vaccination. But generally speaking each person ought to be able to choose and each case ought to be judged and treated separately, and the outcome ought to be dependent on necessity. (Female, age 16/17)

Around half of the older students (aged 16-18), and at least 18 per cent in all groups, refused to choose any of the options. This was a definite choice as they had not been presented with 'none of these' or 'don't know' as an option.

I don't want to choose any of them because it is so unnatural. I just want to live life without ID cards or chips in me or drugs to calm me down! Just leave me alone! Just accept what humans are!!! (Female, age 11/12)

Other reasons for rejecting any option were that 'altering people en masse' is dangerous, removes choice and is totalitarian, and, that aggressiveness is not always a bad thing. Another group wrote that they were reluctant or did not want to choose but 'if I had to choose' went on to opt for the non-permanent, non-genetic option. For this group, taking pills twice a day at least allowed choice. 


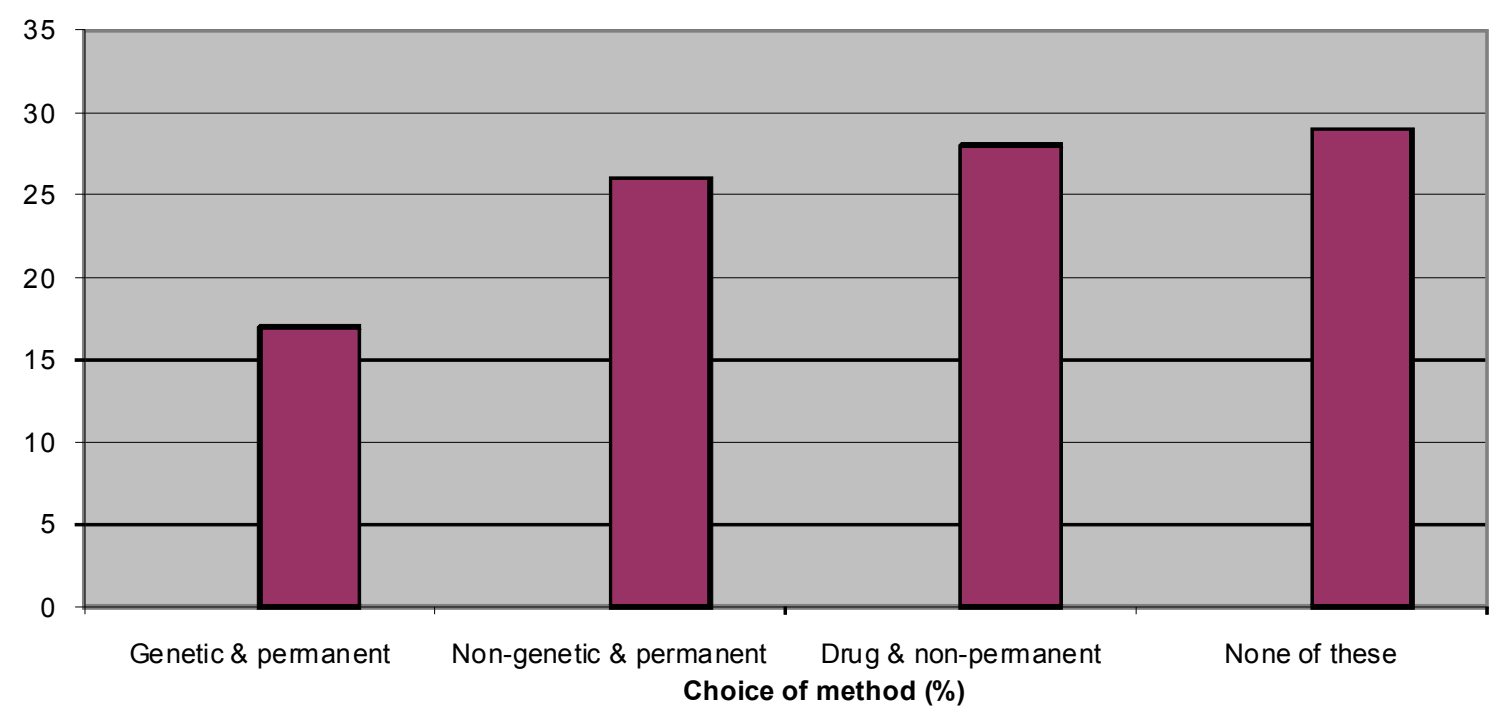

To be honest I would prefer not to choose any of the options and believe that humans as individuals should be valued and given free will and the responsibility to make a decision for themselves. Thus if $I$ had to choose one on principle it would be option $C$ (non-drug non-permanent], although I tend to think that those more angled towards aggression would not take the tablets and thus this would not have been very effective. I think that to an extent we should not want to have everyone completely non-aggressive because I think it could turn to critical consequences with us all turning into robots. (Female, age 17/18)

Some suggested alternative social measures to reduce aggression:

I would not choose any of the above as they are all methods that lead to further control by governments and a restriction of our freedom. Surely it is always better to try and reduce aggression by talking, teaching and learning because in the end this is always going to be more ethically correct than filling someone full of drugs. (Male, age 16/17)

Three main features emerged; firstly, a major reaction against the idea of losing one's freedom to choose how to act on a daily basis to a global power. Secondly, the enhancement of one's mental faculties seems to have struck a different chord from that of bodily enhancement. Although not explicitly stated, there seemed to be a sense in which aggression and the ability to express that aggression was linked with the ability to act upon and express one's autonomy; as in responding to a totalitarian system.

In my opinion I wouldn't vote [for] any - and hope no other would. - but if I had to choose one (which we would in this increasingly restrictive society _ and lack of freedom) it would be c) as it would 
give me choice not to take the drug because - emotions are what makes us human take this away and we are mindless zombies without even realising it. - This is not enhancement - this is suppression. (Male, age 17/18, his emphasis)

Genetic modification came across as less acceptable than using chemicals in the water only due to the difficulties associated with its implementation; being seen as 'less natural'. But for those few who were pro-genetic enhancement it was seen as more effective in the long-term.

Older students were shown two movie clips from The Island and asked to consider whether we need to choose between methods that are allowed for treating a medical problem and methods allowed for enhancement.

\section{Individual choice, autonomy and regulation}

Having strongly asserted the individual's right to choose and overwhelmingly rejected any so-called enhancement being imposed, students were then asked whether there was a need for any regulation. A clear rejection of forced, and sometimes concealed, enhancement did not mean that there was widespread support for a complete freedom to choose. Like the bioethicists Savulescu and McGee, some did simply accept that we should trust people to choose but more commonly students thought about the context of individual choice and the cumulative effects of such choices:

Yes, [we need guidelines] because the need for resources and technicians for strictly medical treatment is being taken up by consumerist cosmetic surgery industry. (Male, age 17/18)

Yes, [we need guidelines] but you should be allowed if you NEED THEM. It shouldn't be a matter of free will otherwise people with lots of money shall be more and more artificial. (Male, age 16/17)

Another common concern that emerged across the groups was the perceived threat to what makes us human and our human values, echoing Habermas (2003) and Fukuyama (2002).

Obviously this will lead to a lot of debate but I think yes, there must be guidelines to prevent too - extreme - a change as this could lead to purely artificial people we can no longer call human.

(Female, age 16/17)

Yes we do [need guidelines] otherwise what is stopping us from becoming man-made robots with the ability of altering ourselves however we choose to and wish to. Providing someone with medical care in order for them to live a normal life has justification however enhancement are just abusing our abilities to do so.

(Female, age 17/18)

Asked who should be consulted in the process of making regulation 'the public', 'the public including children' and 'experts' were equally and most frequently chosen. 


\section{Conclusion}

Our key findings suggest that most students were happy to imagine 'upgrades' but more likely to question the practice of enhancement in real life. The minority who declined even to imagine enhancements generally maintained this viewpoint throughout the debate. The majority who were initially pro-enhancement began to question their position, while the minority who were unclear at the start moved toward an anti-enhancement position. This may have been due to taking part in the session and discussion. Cobb and Hamlett's report on the 2008 National Citizens' Forum on Human Enhancement in the USA, found that following a deliberative forum panellists "became more worried and cautious about the prospective benefits of the human enhancement technologies". ${ }^{28}$

The issues of naturalness and necessity were prevalent, with little differentiation by gender. Students could desire enhancement 'imaginatively', but they also valued the naturalness of their given bodies, with all the concomitant uncertainties and fallibilities this engenders. They would fiercely defend the right for the majority of society to have access to the possibility of enhancements, with the significant caveat that this will be done fairly and be well regulated and carry the responsibilities concomitant with such rights. But they would also ameliorate such freedoms with discussion of 'necessity', for individuals and society.

The young people did not have the space of a book or journal article to develop their views, unlike bioethicists, so their responses were more comparable with the public output of experts in the media. The young people were less certain and less decided than the experts, not necessarily because they were less knowledgeable but sometimes because they took broader considerations into account. In the arguments for enhancement they asserted individual freedom of choice most strongly and none mentioned a moral or ethical duty to enhance and to improve on nature. However, they also argued that individuals had to bear the responsibilities for choices they had made. The difference in context is that the young people were thinking about choices people can make for themselves, since we did not focus on enhancement through reproductive choices. This removed the moral issues raised by genetic testing and termination of pregnancy or selection and discarding of embryos, making the topic more acceptable to the schools, especially the primary school involved. Given the respondents' stress on individuals making responsible choices it is unlikely that they would have fully supported the view that parents should be free to choose for their children.

The dominant framework for considering what people should do was not a utilitarian one in the sense employed by prominent bioethicists including Harris and Savulescu. Following a discussion of a deaf lesbian couple seeking to 'deliberately create' a deaf child Savulescu concludes that;

Increasingly people will seek to us e medicine to improve their lives in ways that others $m$ ay disa gree with. And som e of these improvements will not be in term $\mathrm{s}$ of prevention or trea tment of 
disease, but in the achievem ent of other goods in life... As rational people we should all form our ideas about what is the best life. ${ }^{29}$

For the young people the freedom to choose was important but there was a responsibility to take into account what would happen if everyone freely made their own choices. In other words, they implicitly employed the Kantian maxim that the individual "act only in such a way that you can will that the maxim of your action should become a universal law". Some enhancements would no longer be enhancements if everyone chose them, for example, if IQ could be enhanced then having a high IQ that meets the criteria for joining Mensa could become commonplace and such a child would no longer be considered 'gifted'. Where people did not consider 'what would happen if everyone did that' then there was a justification for constraining them, limiting choices, introducing regulation in order to protect other people. In Onora O'Neill's account of principled autonomy that "requires we act only on principles that can be principles for all", the moral principles that can be derived from it require the "rejection of injury, of coercion, of slavery, of indifference" to others and the rejection of deception. ${ }^{30}$ The young people particularly emphasised the importance of considering other people, extended to a concern to protect what it is to be human. They constrained choice where it might harm others, destroy or change the human race or destroy what humans value. They did not expect people necessarily to think beyond themselves and their immediate wishes. Therefore, while 'generally speaking people should be free to choose' there was an imperative to intervene where individual choices would have societal repercussions.

\section{Acknowledgements}

This research project was funded by the North West Genetics Knowledge Park (NOWGEN) in Manchester through a collaboration with the ESRC Centre for Economic and Social Aspects of Genomics (Cesagen) at Lancaster University. Thanks also to colleagues in the Philosophy Department at Lancaster for their helpful comments on an earlier draft.

\footnotetext{
${ }^{1}$ Department of Politics Philosophy \& Religion, Lancaster University; School of Health and Medicine, Lancaster University. Correspondence to: m.levitt@lancaster.ac.uk

${ }^{2}$ N. Bostrom and J. Savulescu. 2009. Human Enhancement Ethics. The State of the Debate. In Human Enhancement. N. Bostrom and J. Savulescu, eds. Oxford: Oxford University Press: 1-24; J. Harris. 2007. Enhancing Evolution: The Ethical Case for Making Better Humans. Princeton University Press; R. Naam. 2005. More Than Human. Embracing the Promise of Biological Enhancement. New York: Broadway Books; J. Savulescu. Proceative Beneficence: Why We Should Select the Best Children. Bioethics 2001; 15 (5-6): 413-426.

${ }^{3}$ A.W. Frank. 2003. The Bioethics of Biotechnology. Alternative Claims of Posthuman Futures. In Debating Biology: Sociological Reflections on Health Medicine and Society. S. Williams, L. Birke and G. Bendalow (eds). London: Routledge: 261-270; F. Fukuyama. 2002. Our Posthuman Future. Consequences of the Biotechnological Revolution. New York: Farrar, Straus and Giroux; J. Habermas. 2003. The Future of Human Nature. Polity Press.

${ }^{4}$ H. Lesser. 1988. Technology and Medicine: Means and Ends. In Ethics, Technology and Medicine. D. Braine and H. Lesser (eds). Aldershot: Avebury: pp.46-47.

${ }^{5}$ N. Agar. 2005. Liberal Eugenics. In Defence of Human Enhancement. Oxford: Blackwell; T. Bayne and N. Levy. Amputees By Choice: Body Integrity Identity Disorder and the Ethics of Amputation. Journal of Applied Philosophy 2005; 22 (1): 75-86.
} 


\footnotetext{
${ }^{6}$ M. Hayry. If You Must Make Babies Then At Least Make The Best Babies You Can? Human Fertility 2004; 7: 105-112.

${ }^{7}$ J. Savulescu. Procreative Beneficence: Why We Should Select the Best Children. Bioethics 2001; 15 (5-6): 413-426.

J. Harris. 2007 Enhancing Evolution. The Ethical Case for Making Better People. Princeton: Princeton University Press; G. McGee. 2000. The Perfect Baby: Parenthood in the New World of Cloning and Genetics. New York: Rowman \& Littlefield; R. Nozick. 1974. Anarchy, State, Utopia. New York: Basic Books.

${ }^{8}$ McGee ibid; G. Stock. 2002. Redesigning Humans. Choosing Our Children's Genes. London: Profile Books.

${ }^{9}$ Stock ibid, p.188.

${ }^{10}$ F. Fukuyama. 2002. Our Posthuman Future. Consequences of the Biotechnological Revolution. New York : Farrar, Straus and Giroux

${ }^{11}$ Fukuyama ibid; Habermas op.cit. note 3; J-F. Lyotard (trans. Bennington \& Bolwby). 1991. The Inhuman: Reflections On Time. Oxford: Blackwell.

${ }^{12}$ Frank op. cit. note 3: 261-270; A.W. Frank. Emily’s Scars. Surgical Shapings, Technoluxe and Bioethics. Hastings Center Report March-April 2004: 18-29; J. Glover. 2006. Choosing Children. Genes, Disability, and Design. Oxford: Oxford University Press.

${ }^{13}$ Glover ibid

${ }^{14}$ Stock op. cit. note 8, p. 155 .

${ }^{15}$ HFEA Human Fertilisation and Embryology Authority The HFE Act 2008. http://www.hfea.gov.uk/134.html

${ }^{16}$ M. Levitt, K. Weiner and J. Goodacre. Gene Week: A Novel Way of Consulting the Public. Public Understanding of Science 2005; 14: 67-79.

${ }^{17}$ J. Wilsdon and R. Willis. 2004. See-through Science. London: Demos. http://www.demos.co.uk/files/Seethroughsciencefinal.pdf?1240939425

${ }^{18}$ Robots. 2005. Director: Chris Wedge. Blue Sky Studies, $20^{\text {th }}$ Century Fox; Bicenntenial Man. 1999. Director: Chris Columbus. USA: Columbia Pictures and Touchstone Pictures; The Island. 2005. Director: Michael Bay. USA: Dreamworks.

${ }^{19}$ Robots 2005 DVD scene 8.

${ }^{20}$ R. Philip.Pistorius masters quick step, Telegraph.co.uk, 27/4/05. http://www.telegraph.co.uk/sport/main.jhtml?xml=/sport/2005/04/27/sophil27.xml\&sSheet=/sport/200 5/04/27/ixothspt.html

${ }^{21}$ Quoted in Stock op. cit. note 8, p.188.

${ }^{22}$ Frank 2003 op. cit. note 3; Frank 2004 op. cit. note 12.

${ }^{23}$ F. K. O'Neill. Uncanny Belongings: Ethics and the Technologies of Fashioning Flesh. Unpublished $\mathrm{PhD}$ thesis. Lancaster 2007; E. Parens. 1998. Enhancing Human Traits. New York: Hastings Center; T. Shakespeare. 2003. Rights, Risks and Responsibilities: New Genetics and Disabled People. In S. Williams L. Birke and A. Bendelow, eds. Debating Biology: Sociological Reflections on Health, Medicine, and Society. London: Routledge; 198-209.

${ }^{24}$ Bayne and Levy op. cit. note 5, p. 85.

${ }^{25}$ C. Elliot. 2003. Better Than Well: American Medicine Meets the American Dream, New York: W.W. Norton \& Co.

${ }^{26}$ Harris op. cit. note 7 .

${ }^{27}$ Initially all children were asked if they had heard of genetic modification. Almost all those in year 7 (age 11 or 12) and above and about a quarter of those in year 6 (age 10 or 11) had heard of GM and could accurately explain it. The most frequent examples they gave were GM food and 'designer' babies.

${ }^{28}$ North Carolina State University. 16 July 2008. Press release: Study shows increased education on nanotech, human enhancement increases public concern. www.eurekalert.org/pub releases/200807/ncsu-ssi071608.php.

${ }^{29}$ J. Savulescu. Deaf Lesbians, "Designer Disability," and the Future of Medicine. British Medical Journal 2002; 325: 771-773.

${ }^{30}$ O. O’Neill. 2002. Autonomy and Trust in Bioethics. Cambridge: Cambridge University Press: $95 f$.
} 